\title{
Biocharring of natural fibers of insect and plant origin: a green route for the production of 'carbon-based charge storage nanomaterials'
}

\author{
Amarish Dubey ${ }^{1} \cdot$ Himanshi Jangir ${ }^{1} \cdot$ Shourya Verma $^{2} \cdot$ Manav Saxena $^{3} \cdot$ Sabyasachi Sarkar $^{4} \cdot$ Deepu Philip $^{1}$. \\ Mainak Das ${ }^{1}$
}

Received: 25 February 2018 / Accepted: 24 July 2018 / Published online: 4 August 2018

(c) The Author(s) 2018

\begin{abstract}
Futuristic energy materials are expected to be biocompatible, green, sustainable and economical. One of the ways to develop such energy storage materials is by utilizing natural sources such as plants, animals, and insects. Autotrophs fix nitrogen and carbon in the atmosphere through rhizobium and photosynthesis, respectively, which are later consumed by animals and insects as energy sources. Biocharring these plants and insects derived products that could help us regain this carbon and nitrogen in the form of biocharred energy materials. Insect-derived Tassar cocoon, Mulberry cocoon, and Tassar silk thread give N-doped carbon matrix upon biocharring which is further processed to obtain reduced graphene oxide, whereas plant-derived Jute gives a pure carbon matrix on biocharring, all four materials show typical properties of charge storage. Exploring further on these natural charge storage materials will help the energy industries to design green charge storage systems. Further, such an approach in future will open up new avenues of business for silk and jute farmers of the world.
\end{abstract}

Keywords Natural fibers $\cdot$ Jute $\cdot$ Silk cocoon $\cdot$ Nitrogen-doped graphene $\cdot$ Energy materials $\cdot$ Charge storage materials

\section{Introduction}

Carbon nanostructures are attractive, environmentally friendly materials for developing electrochemical charge storage devices, which includes capacitors, supercapacitors, and batteries. Owing to the wide degree of polarizability of carbon electrodes, a possibility of tweaking the conductivity by introducing hetero atoms such as nitrogen in the carbon nanostructures [1-4]. The amphoteric nature of carbon and its existence in multiple forms such as powder, fiber, and

Amarish Dubey, Himanshi Jangir have equal contribution.

Mainak Das

mainakd@iitk.ac.in

1 Indian Institute of Technology Kanpur, Kanpur, Uttar Pradesh 208016, India

2 Department of Computing Science and Physics, University of Glasgow, Glasgow, Scotland, UK

3 Centre for Nano and Material Science, Jain University, Bangalore, Karnataka 562112, India

4 Indian Institute of Engineering Science and Technology, Howrah, West Bengal 711103, India sheets, makes it a 'material of choice' for developing charge storage devices.

Since a decade, there has been an increasing industrial demand for producing high-quality raw carbon materials for application in energy storage devices. The most abundant source of carbon is biomass. Photosynthetic machinery fixes carbon and produces biomass in the biosphere. The nitrogenfixing microbes fix nitrogen into the biomass. When the biomass is carbonized at high temperature $\left(>300{ }^{\circ} \mathrm{C}\right)$, in the absence of oxygen, thermal decomposition of the organic matter results in the rearrangement of the atoms during carbonization [5-11]. The resultant material is commonly termed as 'biochar'. The process itself is called 'biocharring'. Biocharring results in the production of carbon materials of myriad geometries and such geometry and quantity of heteroatom further influences the electrochemical performance. Different biomasses were reported as a precursor for the synthesis of charred carbon for usage in charge storage device [12-19]. Thus, the chemical nature of the biomass greatly influences the structure and the properties of biocharred carbon derived from them. It has been observed that abundance of nitrogen in the precursor (raw biomass) results in significant doping of nitrogen in the biocharred nano-carbon matrix. In the present work, we have made a 
comparative study of the structures and the electrochemical properties of two forms of biocharred carbon obtained from raw silk cocoon and jute. Silk is a protein fiber of insect origin, with high nitrogen content $(15 \%)$, whereas jute is a carbohydrate fiber with almost no nitrogen. The working hypothesis of this study is to test the electrochemical performance and the suitability of these two kinds of biocharred carbon for developing charge storage devices, where one is having natural nitrogen doping viz., biocharred silk and the other is pure carbon viz., biocharred jute. The overall layout of the work is shown in Fig. 1.

\section{Materials and methods}

\section{Electrode material synthesis}

The synthesis of electrode material consists of a three-step reaction: (a) biocharring of the biomass, (b) oxidation of biocharred material and (c) reduction of oxidized biocharred material. These three steps were followed for three investigating materials (Tassar cocoon, Mulberry cocoon and, Tassar silk thread) individually as shown in Fig. 2. Biocharring or pyrolysis of these plant and insect-derived organic materials was done using previously reported reaction condition [13]. In brief, the material was cut into small pieces and was kept in a muffle furnace using alumina boat. The argon gas at required flow was allowed to run for $15 \mathrm{~min}$ before the furnace was switched on, to remove the already present air and set the desired atmosphere for the reaction. The temperature of the furnace was raised to $400{ }^{\circ} \mathrm{C}$ with the ramp rate of $5{ }^{\circ} \mathrm{C} / \mathrm{min}$. The furnace was kept on for a period of $4 \mathrm{~h}$ and then turned off to allow slow cooling till it attains room temperature. The biocharred material was crushed in pestle and mortar and was packed in a Whatman filter paper to remove impurities using acetone in Soxhlet apparatus as reported previously [6-8, 20, 21]. This was then allowed to dry and then was oxidized using $20 \mathrm{ml}$ of $\mathrm{HNO}_{3}$ diluted with water in 2:1 for every $1 \mathrm{~g}$ of charred carbon with continuous stirring at $60{ }^{\circ} \mathrm{C}$ for $24 \mathrm{~h}$. After $24 \mathrm{~h}$, the solution turned dark brown,

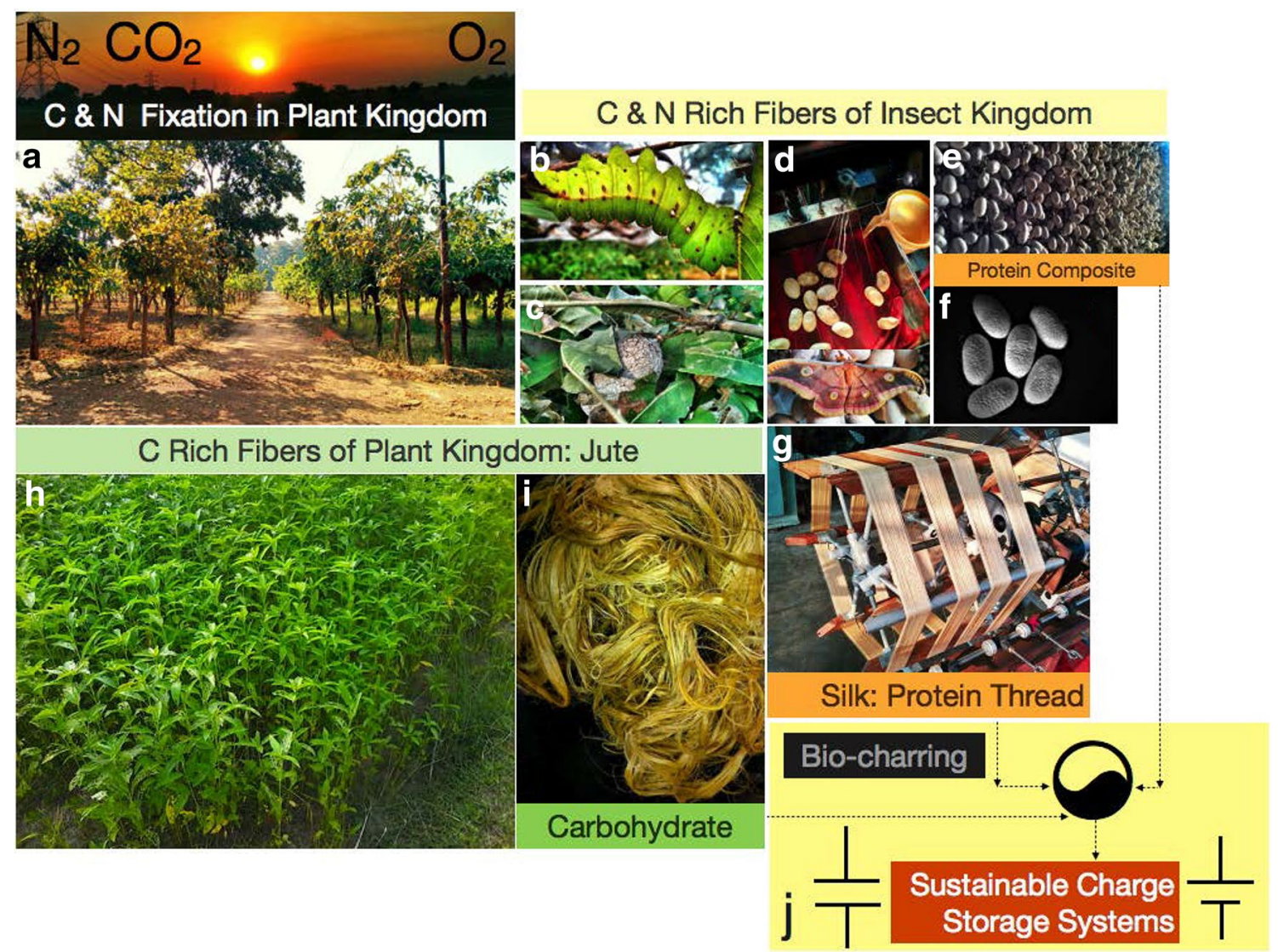

Fig. 1 Overall philosophy of the work. a Plant kingdom fixes carbon and nitrogen from atmosphere. A Tassar silk producing forest, where the wild Tassar silk grows. b Tassar silkworm. c Silkworm feeding on leaves. d Tassar silk cocoon ready for reeling and silk moth (Antheraea mylitta). e Tassar silk cocoon, a composite of fibroin and sericin protein. f Bombyx mori silk cocoon. g Tassar silk thread, a protein thread made up of fibroin. h Jute crop. i Jute fiber, a carbohydrate fiber. $\mathbf{j}$ Developing charge storage devices from the biocharred carbon obtained from silk and jute 
Fig. 2 Graphical schematic showing the preparation of biocharred carbon from silk cocoon and silk thread

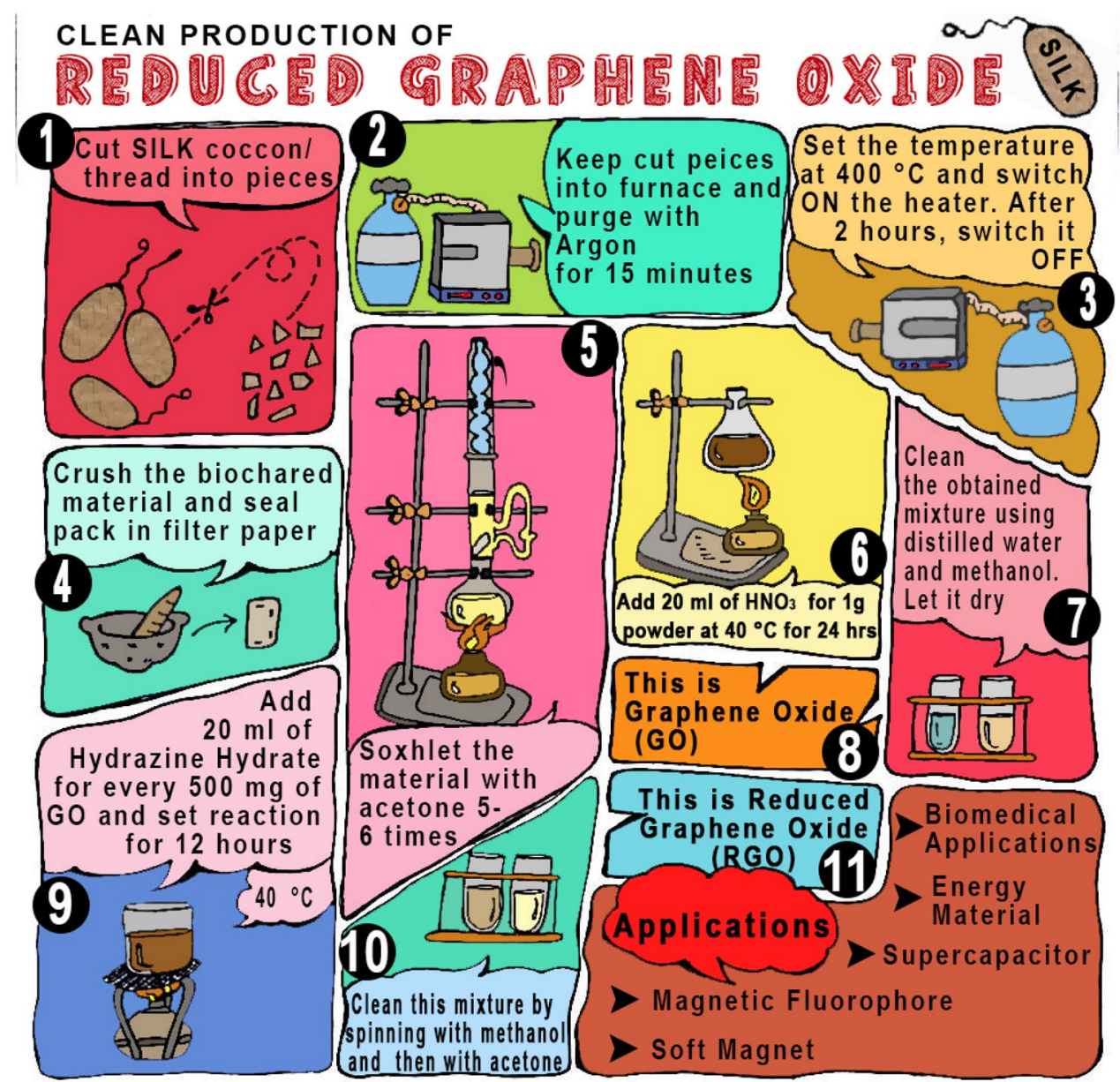

marking the completion of the oxidation process. This solution was centrifuged and washed using deionized water and then with methanol until the supernatant became transparent with $\mathrm{pH}$ 6-7. This dark brown material is the oxidized carbon which was dried and further reduced using hydrazine hydrate. $20 \mathrm{ml}$ of hydrazine hydrate per $500 \mathrm{mg}$ of oxidized carbon was taken and the mixture was stirred continuously at $40{ }^{\circ} \mathrm{C}$ for $12 \mathrm{~h}$. The mixture changed its color to black after $12 \mathrm{~h}$. The reduced carbon was cleaned with methanol. This reduced charred carbon was further characterized using different microscopic and spectroscopic techniques and then was used as electrode material. Jute, a plant biomass, was processed through one step, as shown in Fig. 3. It was cut in small pieces and biocharred at $400{ }^{\circ} \mathrm{C}$ temperature in an argon atmosphere. This charred material was cleaned using acetone in soxhlet apparatus as described above.

\section{Characterization}

Scanning electron microscopy (SEM) was performed using Carl Zeiss (Model Number-EVO18) Scanning Electron Microscope operated at $10 \mathrm{kV}$. The samples were sputter coated with gold using SC7620 Mini Sputter Coater by Quorum Technology. Atomic force microscopy (AFM) analysis was performed using Agilent Technologies Atomic Force Microscope (Model 5500) in ACAFM mode. After calibration, the scanner model N9520AUSO8380185xml was used for the imaging at room temperature and at a scanning speed of 2.0 lines per second. Microfabricated silicon nitride cantilevers with resonance frequencies $(f)$ of 181 and $349 \mathrm{kHz}$ were used. Pico View ${ }^{\circledR}$ 1.8 and Pico Image ${ }^{\circledR}$ Basic software were employed for data acquisition and analysis, respectively. Transmission electron microscopy (TEM) was performed using FEI Titan G2 60-300 TEM. Fourier Transform Infrared Spectroscopy (FTIR) analysis was performed using PerkinElmer FTIR spectrum BX spectrometer, operated in the range of $400-4000 \mathrm{~cm}^{-1}$. X-ray diffraction (XRD) analysis was performed using X' Pert powder-PANalytical XRD at $25{ }^{\circ} \mathrm{C}$ and wavelength $\mathrm{K}$-Alpha1 in the angular range

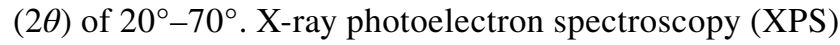
analysis was performed using PHI 5000 Versa Prob II, FEI. XPS and SEM were performed for both raw and biocharred materials obtained from corresponding materials. 
Fig. 3 Graphical schematic showing the preparation of biocharred carbon from jute fiber

\section{LABQRATORY PRPPARATION QE BIOCHARRED JUTE}
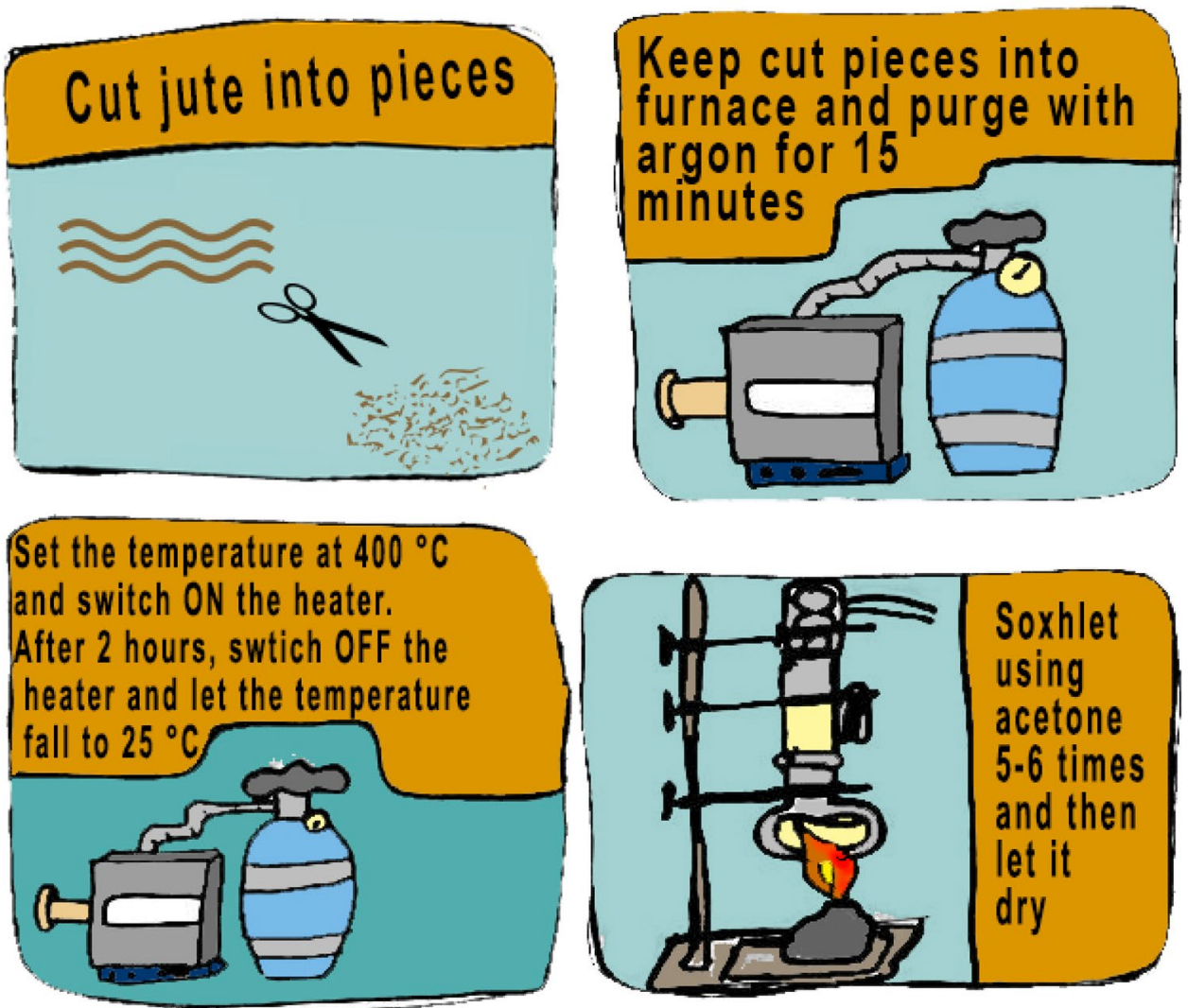

\section{Electrode and device preparation}

A powdered sample of $50 \mathrm{mg}$ was mixed with $3 \mathrm{ml}$ isopropyl alcohol (IPA) and $50 \mu \mathrm{l}$ Nafion (1:10 dilution in water) by sonication. For electrode preparation, this suspension was spray-coated on a graphite sheet (dimensions $=2 \times 1 \mathrm{~cm}$ ). For device preparation, two such electrodes were taken (coated sides facing each other) and a semipermeable membrane along with the electrolyte was sandwiched between them, as mentioned in our previous publications $[6,22]$.

\section{Electrochemical testing of electrode and device}

Electrochemical tests were conducted on ZIVE SP1 singlechannel electrochemical workstation with three electrode arrangement, with $\mathrm{Ag} / \mathrm{AgCl}$ electrode as the reference electrode, platinum wire as the counter electrode and the synthesized material as the working electrode. To examine the performance of four proposed electrode materials [Tassar-reduced graphene oxide (RGO), Mulberry-reduced graphene oxide (RGO), Tassar thread reduced carbon
(RC), and biocharred Jute], cyclic voltammetry was conducted for each electrode in $1 \mathrm{M} \mathrm{H}_{3} \mathrm{PO}_{4}$ as the electrolyte at different scan rates. After obtaining the best electrode material of four proposed materials from the above comparison, further tests were performed only for this material. For this material, the best biocompatible aqueous electrolyte was explored out of available choices, the salts of sodium, potassium and weak biocompatible acid $\mathrm{H}_{3} \mathrm{PO}_{4}$ were examined by testing the electrode in four different electrolytes, namely $1 \mathrm{M} \mathrm{Na}_{2} \mathrm{SO}_{4}, 1 \mathrm{M} \mathrm{H}_{3} \mathrm{PO}_{4}, 1 \mathrm{M} \mathrm{NaCl}$, $1 \mathrm{M} \mathrm{KCl}$ at different scan rates $(\mathrm{mV} / \mathrm{s})$. The charge-discharge and electrochemical impedance analysis were also conducted on ZIVE SP1single channel electrochemical workstation with three electrode arrangement for the best found electrode material. The charge-discharge was conducted for the electrode at different scan rates of 1, 2, 3, and, $5 \mathrm{~mA} / \mathrm{cm}^{2}$ with $1 \mathrm{M} \mathrm{H}_{3} \mathrm{PO}_{4}$ to investigate the behavior and performance of the electrode. The life cycle analysis was done by performing 10,000 cycles of charge-discharge in the same electrolyte at a current density of $5 \mathrm{~mA} / \mathrm{cm}^{2}$. 


\section{Results}

The schematic for preparation of reduced graphene oxide from Tassar cocoon and Mulberry cocoon and reduced carbon from Tassar silk thread is shown in Fig. 2. Biocharred carbon obtained from Jute is shown in Fig. 3.

The four raw materials that we explored are shown in Fig. 4a-d. Tassar cocoon or Antheraea mylitta shown in Fig. 4a was obtained from Jharkhand, India. Mulberry cocoon or Bombyx mori shown in Fig. 4b was obtained from Karnataka, India. Tassar silk thread obtained from Tassar cocoon is shown in Fig. 4c. Jute is shown in Fig. 4d. Tassar cocoon, Mulberry cocoon and, Tassar silk thread show sheet-like structure as shown in Fig. $4 \mathrm{e}-\mathrm{g}$, respectively [7, 9], and Jute exhibits thin tube-like structure as shown in Fig. 4h [6]. Presence of carbon and nitrogen in Tassar cocoon, Mulberry cocoon, Tassar silk thread and, Jute are shown by XPS broad spectra in Fig. 4i-1. Jute has least amount of nitrogen (2.4\%) and the Tassar cocoon has
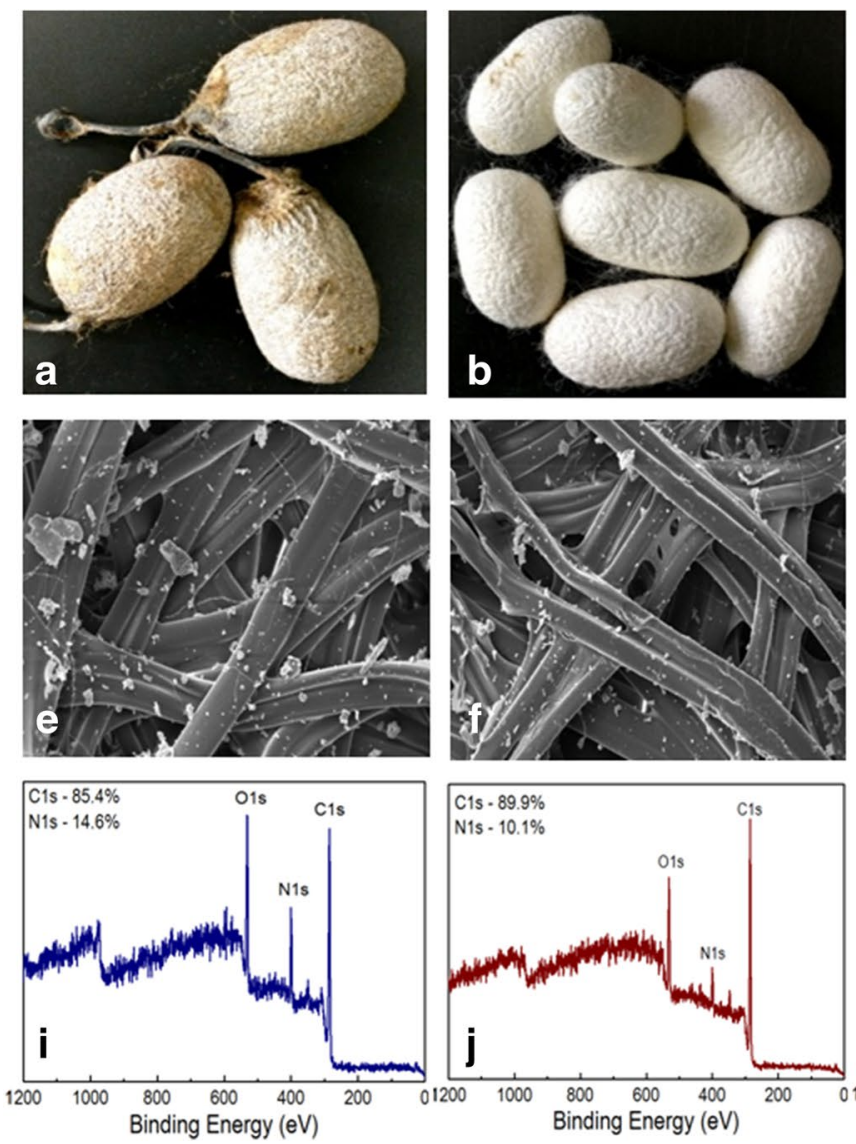

Fig. 4 Insect-generated and plant-generated fibrous materials. a, b. Tassar cocoon (Antheraea mylitta) and Mulberry cocoon (Bombyx mori). c Processed Tassar silk thread. d Jute. e-h SEM images of raw
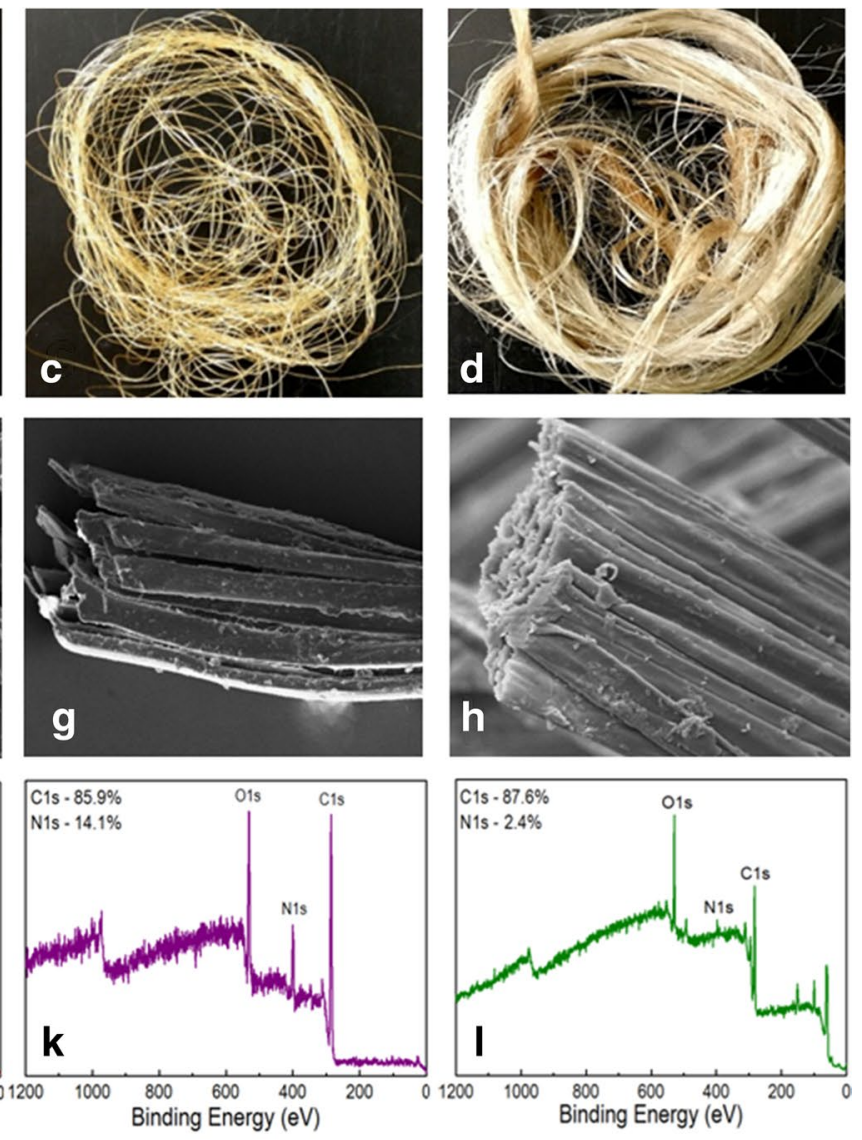

the highest amount of nitrogen (14.6\%) among all four materials.

The optical images of the reduced graphene oxide obtained from Tassar cocoon and Mulberry cocoon, reduced carbon from Tassar silk thread and biocharred carbon from jute are shown in Fig. 5a-d, respectively. The corresponding XRD patterns are shown in Fig. 5e-h, show a prominent peak at around $2 \Theta=25^{\circ}$ corresponding to plane indices of (002) indicates that each sample contains good graphitic structure. The Raman spectra for each of the four samples are shown in Fig. 5i-1, show two prominent peaks at around 1347 and $1584 \mathrm{~cm}^{-1}$ corresponding to $\mathrm{D}$ and $\mathrm{G}$ band, respectively, supporting the presence of the graphitic structure. Tassar cocoon and Mulberry cocoon derived RGO, and Tassar silk thread derived reduced carbon possess 2D band communicated by spectrum at 2687 and $2678 \mathrm{~cm}^{-1}$, respectively. The D-band and G-band are merged and thus confirm the higher defects density due to presence of hetero atom, $\mathrm{O}$-containing groups and the structural defects, etc. in synthesized rGO. The 2D band is most likely suppressed by "Pauli blocking effect" [23-28]. FTIR spectra are shown in

Tassar cocoon, Mulberry cocoon, Tassar silk thread and Jute, respectively. i-l XPS broad spectrum of Tassar cocoon, Mulberry cocoon, Tassar silk thread and Jute surface, respectively 

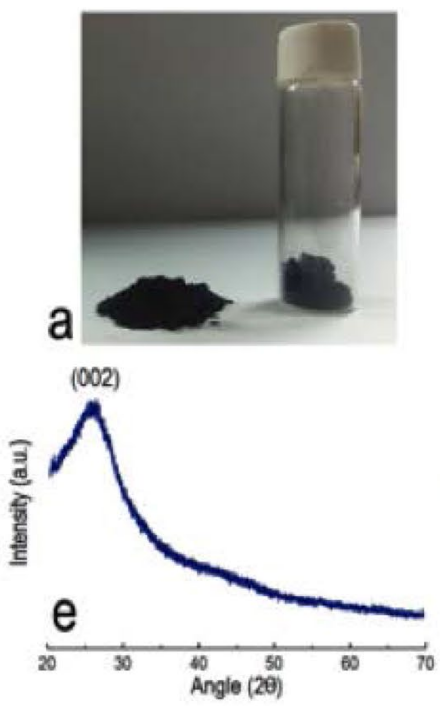

b
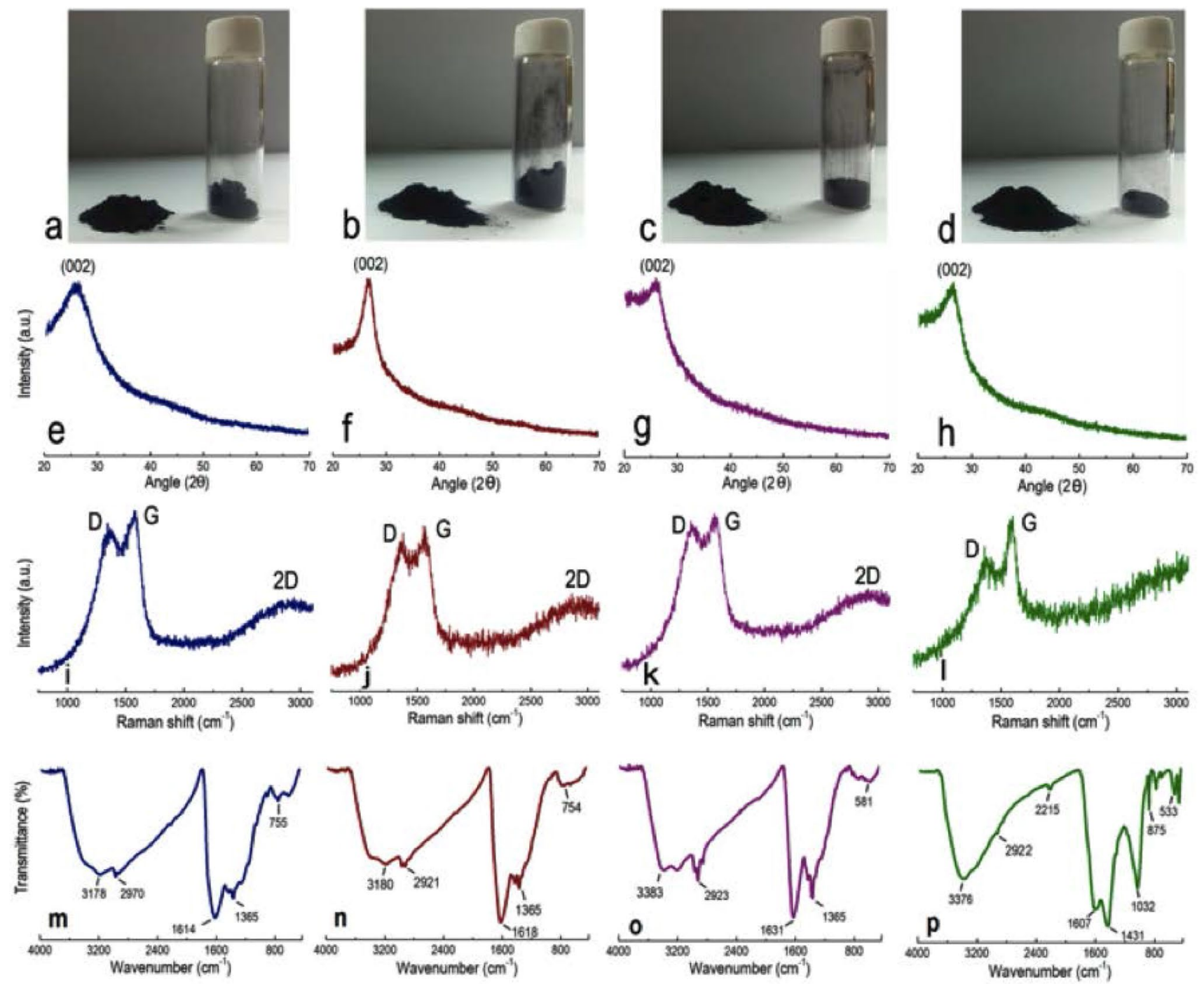

Fig. 5 XRD, Raman Spectra and FTIR for Tassar RGO, Mulberry RGO, Tassar silk thread-derived reduced carbon and Jute-derived biocharred carbon, respectively. a-d Synthesized samples. e-h XRD patterns. i-l Raman spectrum. m-p FTIR patterns

Fig. $5 \mathrm{~m}-$ p, the four peaks approximately common for four materials are around 3100-3400, 2910-2980, 1600-1720 and $1365-1440 \mathrm{~cm}^{-1}$ corresponding to hydroxyl $(-\mathrm{OH})$ group, $\mathrm{C}-\mathrm{H}$ stretching, carbonyl $(\mathrm{C}=\mathrm{O})$ group and ether or epoxide $(\mathrm{C}-\mathrm{O})$ bond, respectively. Presence of ether group is also mapped to peaks at 1032 and $750-875 \mathrm{~cm}^{-1}$ seen in jute derived biocharred carbon. Multiple small peaks observed in range $1200-1300 \mathrm{~cm}^{-1}$ represent $\mathrm{C}-\mathrm{N}$ stretching for RGO and reduced carbon $[6,7,9]$.

Survey XPS spectra shown in Fig. 6a-d, shows all the four samples contain more than $75 \%$ carbon, and Jute derived biocharred carbon outstands other three samples with a total of $95.1 \%$ carbon. Nitrogen content in Jute derived biocharred carbon is $4.9 \%$, Tassar cocoon-derived RGO is $24.9 \%$, Mulberry cocoon-derived RGO is $23.8 \%$ and Tassar silk thread-derived reduced carbon is $14.1 \%$.
XPS narrow spectrum corresponding to carbon $(\mathrm{C} 1 \mathrm{~s})$ in four samples are shown in Fig. 6e-h. The $\mathrm{C} 1 \mathrm{~s}$ spectrum revealed the presence of three types of carbon bonds: $\mathrm{C}-\mathrm{C} /$ $\mathrm{C}=\mathrm{C}(284.6 \mathrm{eV})(\mathrm{C}-) \mathrm{C}-\mathrm{N}(285.9 \mathrm{eV}), \mathrm{C}=\mathrm{C}-\mathrm{N}(286.5 \mathrm{eV})$, $\mathrm{C}=\mathrm{N} / \mathrm{C}=\mathrm{O}(287.9 \mathrm{eV})$ and $\mathrm{O}-\mathrm{C}=\mathrm{O}(289.0 \mathrm{eV})$, respectively $[9,19]$. XPS narrow spectrum corresponding to nitrogen (N1 s) in four samples are shown in Fig. 6i-l, peaks around 397 and $399.9 \mathrm{eV}$ correspond to nitride bond and nitrogen bond in an organic matrix, respectively, a peak around $398 \mathrm{eV}$ is seen in RGO obtained from Tassar cocoon corresponds to cyanide bond [9]. In earlier works with carbon materials, similar XPS spectra have been observed [26-28].

AFM and TEM studies for the biocharred materials have been discussed in Fig. 7a-i. AFM scan of Tassar cocoon derived RGO in Fig. 7a shows a single-layered sheet-like structure of around $10 \mathrm{~nm}$ which corroborates with the 

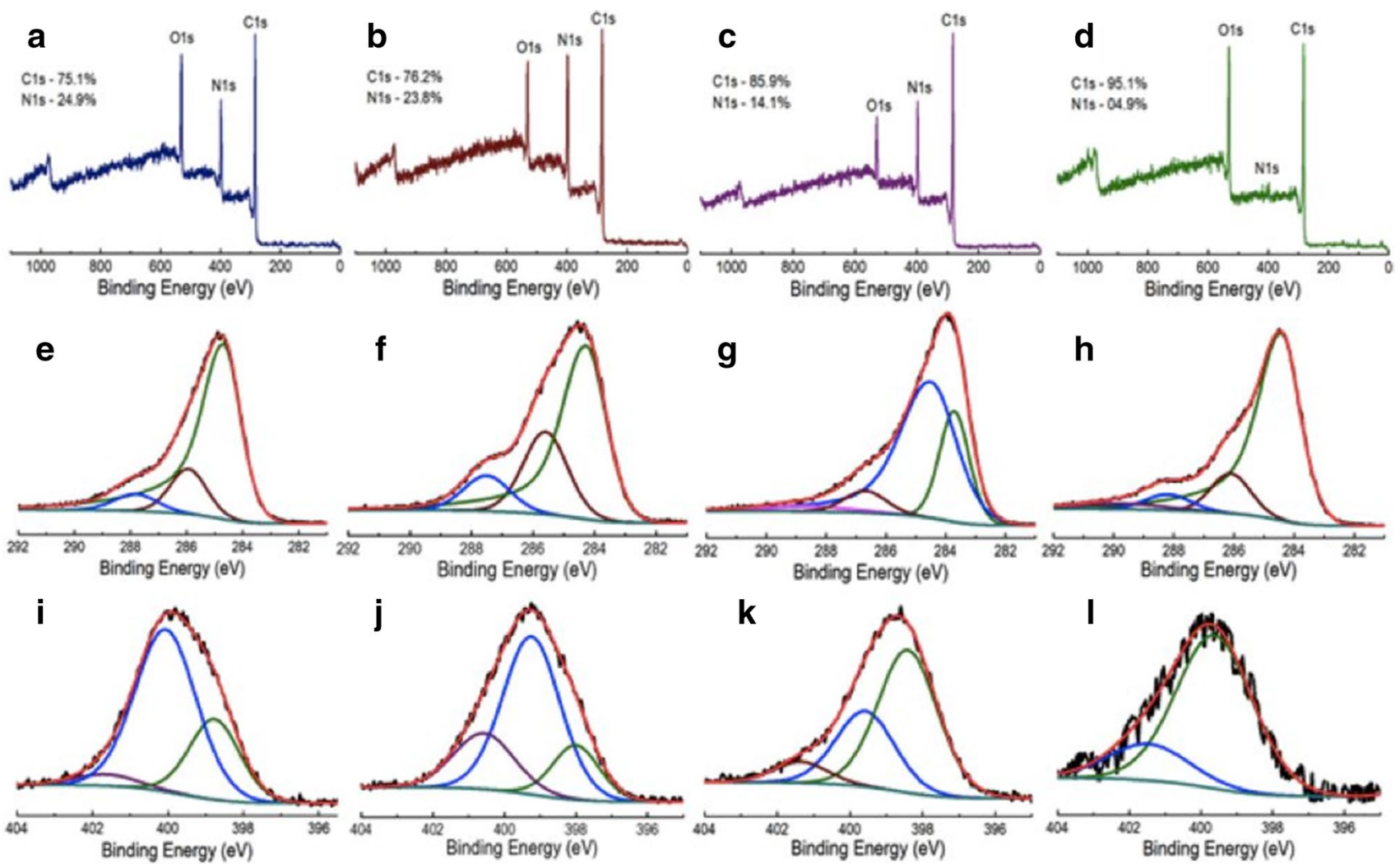

Fig. 6 XPS analysis of synthesized materials. a-d Broad spectrum analysis of Tassar RGO, Mulberry RGO, Tassar silk thread-derived reduced carbon and Jute-derived biocharred carbon, respectively. eh XPS narrow spectrum of carbon peaks of Tassar RGO, Mulberry

graphene-like structure in TEM and HRTEM images as shown in Fig. 7e and i, respectively. AFM scan of Mulberry RGO in Fig. 7b shows multiple-layers of sheets of $20 \mathrm{~nm}$ stacked together which is also seen in TEM and HRTEM images in Fig. $7 \mathrm{f}$ and $\mathrm{j}$, respectively. Similar to RGO obtained from Mulberry cocoon, Tassar silk thread derived reduced carbon also has multiple-layered sheet-like structure of around $10-15 \mathrm{~nm}$, with lesser number of layers than the former (Fig. 7c), which upholds with the TEM and HRTEM images shown in Fig. $7 \mathrm{~g}$ and $\mathrm{k}$. AFM scans of Jute derived biocharred carbon in Fig. $7 d_{1}$ does not show sheetlike structure. Another AFM scan in Fig. $7 d_{2}$ shows some deep-hollow zones, which are corroborated by hollow tubelike structure cut parallel to its plane of assembly as shown in TEM image in Fig. 7h. The HRTEM image of biocharred jute shown in Fig. 7i shows that these individual hollow tubes are made up of carbon sheets similar to graphene.

\section{Electrochemical characterization of electrode and device}

The electrode was made by spraying individual materials on graphite sheets (current collector) and the sandwiching

RGO, Tassar silk thread derived reduced carbon and Jute derived biocharred carbon, respectively. i-l Narrow spectrum of nitrogen peaks of Tassar RGO, Mulberry RGO, Tassar silk thread-derived reduced carbon and Jute-derived biocharred carbon, respectively

of electrolyte and semipermeable membrane in between the similar two electrodes became symmetrical device was used to perform cycle voltammetry, charge-discharge, and electrochemical impedance spectroscopy. The area coated with electrode material is $2 \mathrm{~cm}^{2}$ and the material amount is $1 \mathrm{mg}$ per electrode. The initial electrolyte choice was phosphoric acid for electrode testing and comparison, because of its biocompatible nature.

\section{Cyclic voltammetry of electrodes}

The three electrode arrangement was used for cyclic voltammetry of these four different electrode materials. Figure 8a corresponds to comparison among these electrode materials in $1 \mathrm{M} \mathrm{H}_{3} \mathrm{PO}_{4}$ (used as electrolyte) at a scan rate of $300 \mathrm{mV} / \mathrm{s}$ in a voltage window of $0-800 \mathrm{mV}$. The cyclic voltammetry for all electrode materials is almost rectangular and symmetrical about the current axis at 0 . The Tassar RGO (shown in violet) showed outstandingly better specific capacitance (coverage area) and current density. The specific capacitance for Tassar RGO is $284 \mathrm{~F} / \mathrm{g}$ corresponding to $300 \mathrm{mV} / \mathrm{s}$ scan rate, whereas for Mulberry RGO, Tassar silk thread-derived reduced carbon and Jute-derived biocharred

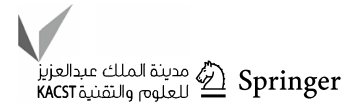




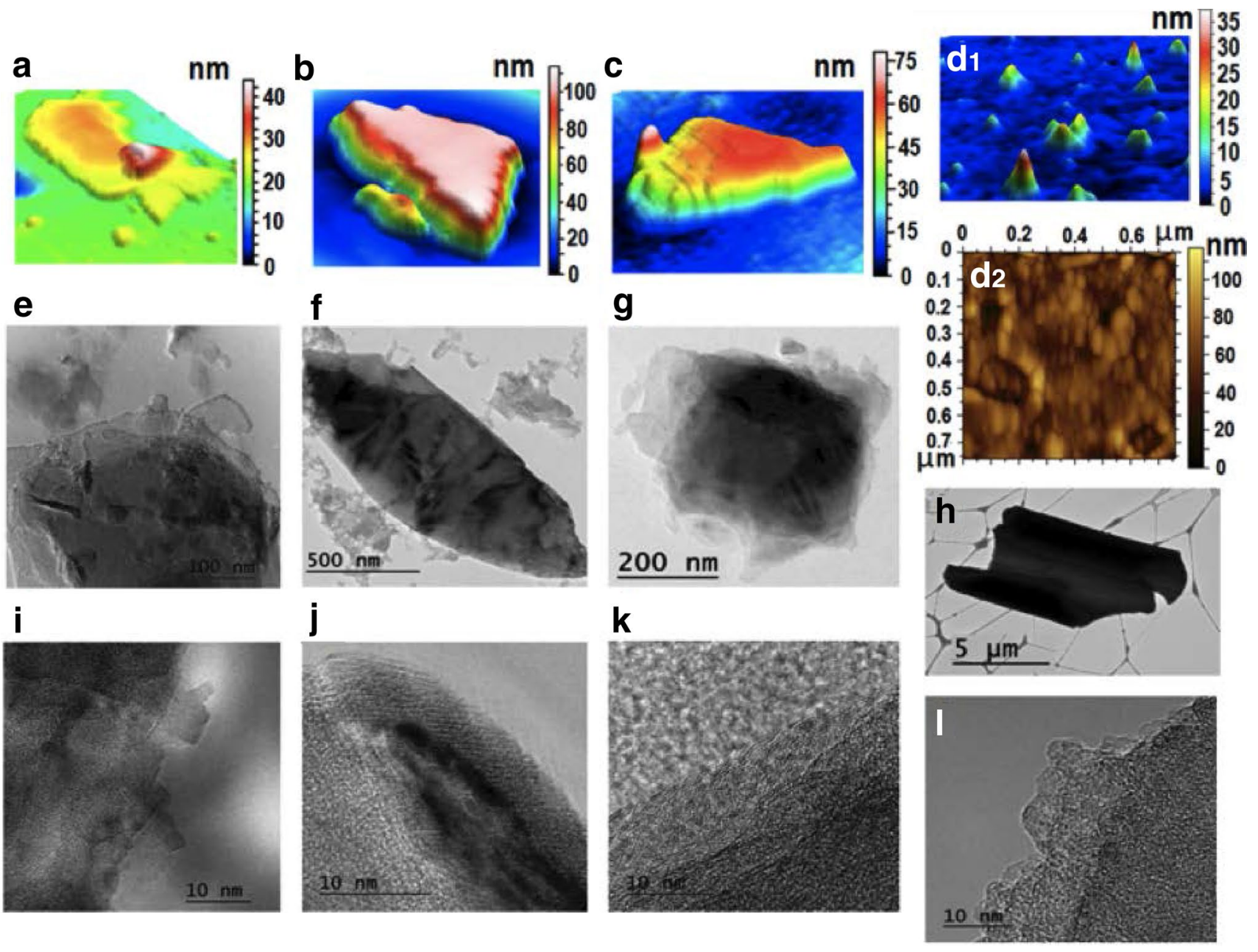

Fig. 7 AFM and TEM analysis of synthesized materials. a-c AFM images of Tassar RGO, Mulberry RGO, Tassar silk thread derived reduced carbon, respectively. $\mathbf{d}_{1}, \mathbf{d}_{2}$ AFM image of Jute derived biocharred carbon. $\mathbf{e}-\mathbf{h}$ TEM images of Tassar RGO, Mulberry RGO,

carbon are 56, 68, and $75 \mathrm{~F} / \mathrm{g}$, respectively. In addition, the current density for Tassar RGO is $0.037 \mathrm{Amp} / \mathrm{cm}^{2}$ whereas that for Mulberry RGO, Tassar silk thread-derived reduced carbon and Jute-derived biocharred carbon is 0.004, 0.02, and $0.01 \mathrm{Amp} / \mathrm{cm}^{2}$, respectively. After concluding Tassar RGO to be the best electrode material of all four materials, the best biocompatible electrolyte was to be found out, so biocompatible and easily available salts and weak acids were explored, namely $1 \mathrm{M} \mathrm{H}_{3} \mathrm{PO}_{4}, 1 \mathrm{M} \mathrm{Na}_{2} \mathrm{SO}_{4}, 1 \mathrm{M} \mathrm{NaCl}$ and, $1 \mathrm{M} \mathrm{KCl}$. Figure $8 \mathrm{~b}$ shows the comparison of the aforesaid electrolytes with Tassar RGO electrode at a scan rate of $300 \mathrm{mV} / \mathrm{s}$ in a voltage window of $0-800 \mathrm{mV}$. It was observed that the biocompatible, weak acid $1 \mathrm{M} \mathrm{H}_{3} \mathrm{PO}_{4}$ showed the prominent specific capacitance and current density as compared to other electrolytes. The Tassar RGO electrode with $1 \mathrm{M} \mathrm{H}_{3} \mathrm{PO}_{4}$ showed a specific capacitance of $284 \mathrm{~F} / \mathrm{g}$ and a current density of $0.037 \mathrm{Amp} / \mathrm{cm}^{2}$ whereas other electrolytes
Tassar silk thread derived reduced carbon and Jute derived biocharred carbon, respectively. i-l HRTEM images of Tassar RGO, Mulberry RGO, Tassar silk thread-derived reduced carbon and Jute-derived biocharred carbon, respectively

with the same electrode showed almost half specific capacitance and current density approximately equating to $180 \mathrm{~F} / \mathrm{g}$ and $0.015 \mathrm{Amp} / \mathrm{cm}^{2}$, respectively. Thus, it can now be concluded that Tassar RGO electrode with $1 \mathrm{M} \mathrm{H}_{3} \mathrm{PO}_{4}$ shows the best electrochemical performance. Now, the electrode and device were investigated by performing cyclic voltammetry in a voltage range of $0-800 \mathrm{mV}$ at different scan rates (as shown in Fig. 8c, at scan rates of 5, 50, 100 and, $300 \mathrm{mV} / \mathrm{s}$ ) for Tassar RGO and $1 \mathrm{M} \mathrm{H}_{3} \mathrm{PO}_{4}$.

In an earlier work, using $\mathrm{H}_{2} \mathrm{SO}_{4}$ as an electrolyte, a characteristic redox couple was observed [9], but with the following electrolytes viz., $1 \mathrm{M} \mathrm{H}_{3} \mathrm{PO}_{4}, 1 \mathrm{M} \mathrm{Na}_{2} \mathrm{SO}_{4}, 1 \mathrm{M} \mathrm{NaCl}$ and, $1 \mathrm{M} \mathrm{KCl}$; we did not observe any such redox couple at any scan rates, which signifies prominent double-layer capacitance and further it shows that the electrode could perform for a longer period of time without any deposition or etching. The cyclic voltammetry for each scan rate is almost 

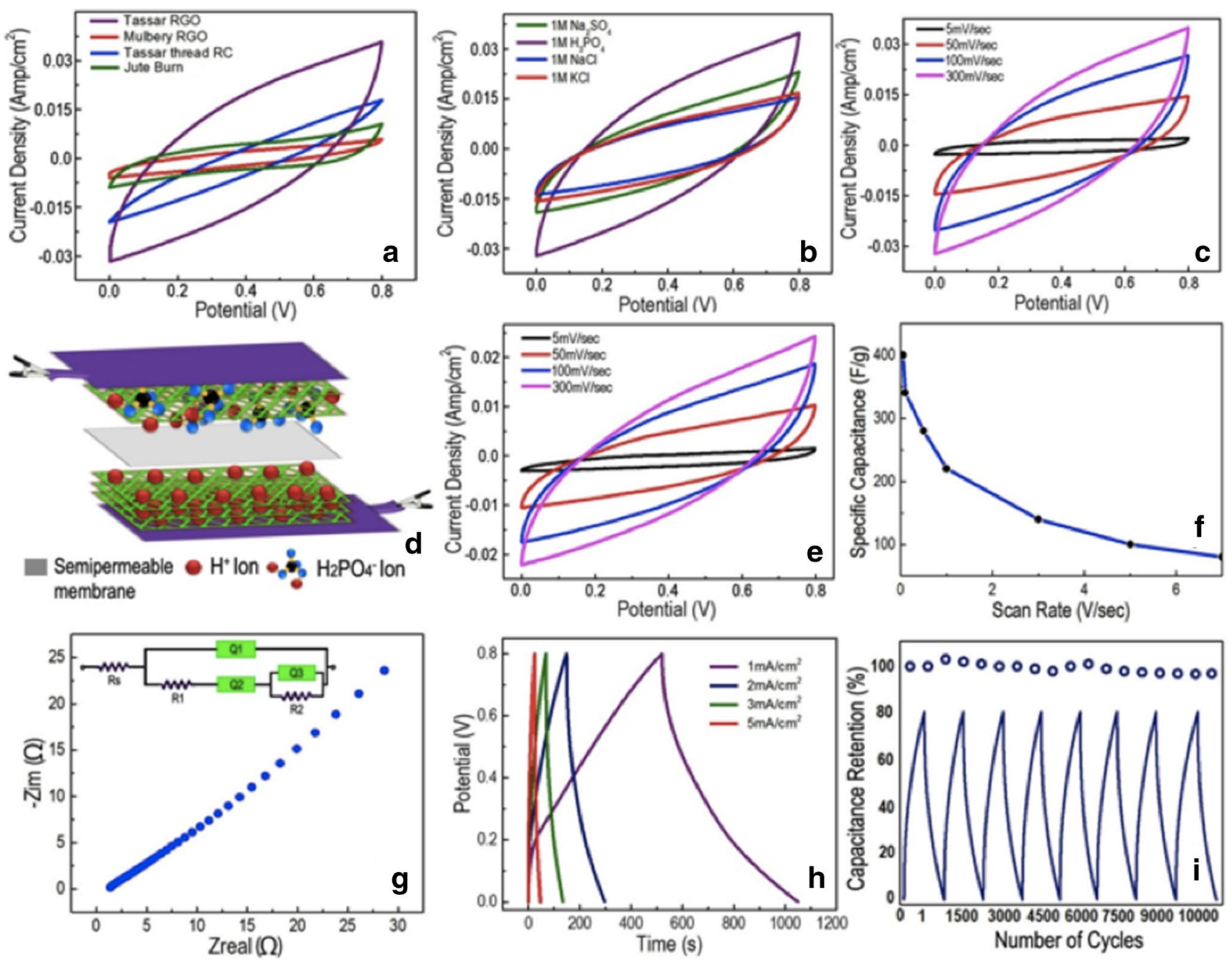

Fig. $8 \mathrm{CV}$, impedance and lifetime analysis. a CV comparison of Tassar RGO, Mulberry RGO, Tassar silk thread-derived reduced carbon and Jute-derived biocharred carbon at a scan rate of $300 \mathrm{mV} / \mathrm{s}$ in $1 \mathrm{M}$ $\mathrm{H}_{3} \mathrm{PO}_{4}$ electrolyte. b CV comparison of Tassar RGO in different electrolytes $\left(1 \mathrm{M} \mathrm{H}_{3} \mathrm{PO}_{4}, 1 \mathrm{M} \mathrm{Na}_{2} \mathrm{SO}_{4}, 1 \mathrm{M} \mathrm{NaCl}, 1 \mathrm{M} \mathrm{KCl}\right)$ at a scan rate of $300 \mathrm{mV} / \mathrm{s}$. c CV of Tassar RGO electrode in $1 \mathrm{M} \mathrm{H}_{3} \mathrm{PO}_{4}$ electrolyte at different scan rates of 5, 50, 100 and, $300 \mathrm{mV} / \mathrm{s}$. d Schematic diagram of a symmetrical charge storage device. e CV of Tassar RGO symmetrical device in $1 \mathrm{M} \mathrm{H}_{3} \mathrm{PO}_{4}$ electrolyte at different scan rates of 5, 50, 100 and, $300 \mathrm{mV} / \mathrm{s}$. f Graph between specific capacitance and scan rate for Tassar RGO electrode. $\mathbf{g}$ Electrochemical impedance spectroscopy (EIS) of Tassar RGO electrode in an aqueous $1 \mathrm{M}$ $\mathrm{H}_{3} \mathrm{PO}_{4}$ electrolyte. h Charge-discharge of Tassar RGO electrode in $1 \mathrm{M} \mathrm{H}_{3} \mathrm{PO}_{4}$ electrolyte at different current densities ranges of $1,2,3$ and, $5 \mathrm{~mA} / \mathrm{cm}^{2}$. i Life cycle analysis by 10,000 cycles of charge-discharge in $1 \mathrm{M} \mathrm{H}_{3} \mathrm{PO}_{4}$ electrolyte at the current density of $5 \mathrm{~mA} / \mathrm{cm}^{2}$ rectangular and symmetrical to the current axis which shows the supercapacitor behavior of the electrode. The specific capacitance corresponding to the scan rate of $5 \mathrm{mV} / \mathrm{s}$ is approximately $400 \mathrm{~F} / \mathrm{g}$ and current density corresponding to the scan rate of $300 \mathrm{mV} / \mathrm{s}$ is $37 \mathrm{~mA} / \mathrm{cm}^{2}$.

\section{Device structure and its cyclic voltammetry}

The symmetrical device has both electrodes of Tassar RGO. The schematic diagram of symmetrical charge storage device is shown in Fig. 8d, where purple layers show thin graphite current collector, green mesh shows electrode material, transparent layer in between shows semipermeable membrane, and spheres show $\mathrm{H}+$ ions and phosphorous ions. As we connect one electrode to the positive terminal of dc supply and other to the negative terminal of the supply, the device forms the Helmholtz double layer and this double layer is prominent for charge storage with other redox and battery effect.

Thus, for electrochemical investigation of the symmetrical device, the cyclic voltammetry is performed with the same electrolyte $\left(1 \mathrm{M} \mathrm{H}_{3} \mathrm{PO}_{4}\right)$ at different scan rates and in a voltage range of $0-800 \mathrm{mV}$ as shown in Fig. 8e. Similar to electrode characterization, the symmetric device curves 
are almost rectangular and symmetrical to current density axis with a maximum current density of $0.025 \mathrm{Amp} / \mathrm{cm}^{2}$ for $300 \mathrm{mV} / \mathrm{s}$ and a minimum of $0.0025 \mathrm{Amp} / \mathrm{cm}^{2}$ at $5 \mathrm{mV} / \mathrm{s}$. All the curves follow the same pattern with no observable redox.

\section{Specific capacitance versus scan rate graph}

The Fig. $8 \mathrm{f}$ shows the graph between specific capacitance and scan rates for Tassar RGO electrode in $1 \mathrm{M} \mathrm{H}_{3} \mathrm{PO}_{4}$ (electrolyte). It can be observed that the electrode is showing very high storage capacity with weak biocompatible electrolyte $\left(1 \mathrm{M} \mathrm{H}_{3} \mathrm{PO}_{4}\right)$, i.e., approximately $400 \mathrm{~F} / \mathrm{g}$ for $5 \mathrm{mV} / \mathrm{s}$ scan rate and as scan rate is increasing the values for specific capacitance decrease but still at $100 \mathrm{mV} / \mathrm{s}$ it has a specific capacitance of $220 \mathrm{~F} / \mathrm{g}$. There may be a possible reason for the decrement in specific capacitance as scan rates increase as the ions may get lesser chance to interact with electrode material with increasing scan rate.

\section{Electrochemical impedance spectroscopy}

Electrochemical impedance spectroscopy (EIS) of Tassar RGO in an aqueous $1 \mathrm{M} \mathrm{H}_{3} \mathrm{PO}_{4}$ electrolyte in the range of $10 \mathrm{kHz}-10 \mathrm{MHz}$ is shown in Fig. 8g. The Nyquist plot between the imaginary impedance versus real impedance shows an almost straight line curve and the inset shows a model equivalent circuit of the setup that signifies series contact resistance and ohmic loss at the electrolyte and electrode contact. Q1 and Q2 are the high-frequency elements that are related to the dielectric character of the coating which may be reinforced by ionic conduction through its pores R1. The low-frequency contribution Q3 is attributed to the double-layer capacitance with inbuilt resistance $\mathrm{R} 2$.

\section{Charge discharge and life cycle of the electrode}

The charge-discharge characteristics of Tassar RGO electrode in $1 \mathrm{M} \mathrm{H}_{3} \mathrm{PO}_{4}$ electrolyte in a voltage range of 0-800 $\mathrm{mV}$ were performed at different current densities of $1,2,3,5 \mathrm{~mA} / \mathrm{cm}^{2}$. Figure. $8 \mathrm{~h}$ shows that the charging and discharging curve almost shows a mirror symmetry within all current densities. The specific capacitance is $426 \mathrm{~F} / \mathrm{g}$ at a current density of $1 \mathrm{~mA} / \mathrm{cm}^{2}$. The charging and discharging times corresponding to the current density of $1 \mathrm{~mA} / \mathrm{cm}^{2}$ are $520,550 \mathrm{~s}$, respectively, which is almost same and this same ratio is same for all current densities so it shows an ideal supercapacitor characteristic. The cyclic voltammetry and charge-discharge show the very ideal performance of the Tassar RGO electrode material so it is important to investigate its stability in terms of life cycle. Figure $8 \mathrm{i}$ shows the life cycle analysis of the Tassar RGO electrode material, in which charge-discharge cycle was run for 10,000 cycles in $1 \mathrm{M} \mathrm{H}_{3} \mathrm{PO}_{4}$ electrolyte at $5 \mathrm{~mA} / \mathrm{cm}^{2}$ current density. It could be observed that the shape and overall time taken for a cycle of all the charge-discharge curves over time is perfectly similar. The charge storage capability is $99.5 \%$ after 10,000 cycles so the specific capacitance retention is $99.5 \%$ even after 10,000 cycles.

\section{Discussion}

During last one decade, a significant amount of work has been carried out, where biocharring process has been utilized to convert a wide range of biomass like cotton, banana peel, recycled paper, dried leaves, silk cocoon, wood waste, etc., to obtain activated porous carbon. Further, such biomass derived carbon has been composited with graphene/CNTs and used for constructing supercapacitors and batteries [5-19, 29-40]. Yet a classification of the chemical origin of these biomass is critical for understanding the electrochemical performance of the biocharred carbon. Here, we tested two different class of biomass viz., a pure protein and a pure carbohydrate. Interestingly, the protein biomass is a rich source of nitrogen. Thus, upon biocharring such a source, there is always a possibility that the carbon matrix will be inherently doped with nitrogen. The presence of this nitrogen could significantly improve the electrochemical performance of the material, as documented in the earlier works [9].

There is another aspect where tremendous interest has been generated for the use of activated porous carbon obtained from biomass viz., stabilizing the lithium-sulfur electrode material for lithium-sulfur battery. Li-S materials are commonly used electrode for high-energy $\mathrm{Li} / \mathrm{S}$ batteries. Yet Li-S compounds have inherently low conductivity, sluggish electrochemical activation and are extremely unstable in the presence of moisture. These anomalous behavior of $\mathrm{Li}-\mathrm{S}$ complex is partly due to the extremely small size of $\mathrm{Li}$ ion and formation of a covalent complex with sulfur ion. Further, a strong affinity of $\mathrm{H}^{+}$ion for sulfur makes these Li-S complex, susceptible to moisture [41]. To stabilize Li-S complex and further improving its conductivity, one approach is caging the complex in a hydrophobic 3-D porous atomic matrix of a carbon material possessing superior electrical properties. Several attempts in this direction is underway where $\mathrm{Li}-\mathrm{S}$ complexes have been stabilized using porous carbon matrix $[34,35,39,40]$. One of the very recent study has shown that if $\mathrm{Li}$ and $\mathrm{S}$ is sequentially entrapped in a hydrophobic conductivity cage of N-doped reduced graphene oxide supercapacitor derived from silk cocoon, it results in a hybrid Li-S-silk supercapacitor [41]. Essentially, Li-S complexes which otherwise are always considered as battery material, could now find wide application in the supercapacitor development [41]. Thus, these studies are highlighting the fact that the chemical origin of 
the biomass is of extreme significance in determining the electrochemical properties of the biocharred, porous carbon obtained from them. The present study is one such systematic attempt to chemically categorize the biomass and then post-biocharring, studying the electrochemical profiles of these materials.

Thus, while summarizing, in the present work, we have explored the electrical and charge storage properties of four plant-derived and insect-derived materials, namely Tassar cocoon, mulberry cocoon, processed Tassar silk thread and, Jute. We expected Tassar cocoon and Mulberry cocoon, both being protein sources, to behave similarly. To our surprise, Tassar cocoon showed better electrochemical profile as compared to Mulberry cocoon. We are presently exploring why there is such a difference between two different protein fibers where nitrogen content is fairly similar. As we aim towards developing green-biocompatible materials, we further explored the performance of Tassar cocoon in four biocompatible/bio-tolerable electrolytes, of which, a combination of Tassar cocoon and $1 \mathrm{M} \mathrm{H}_{3} \mathrm{PO}_{4}$ showed best results. The electrode material is extremely stable with a capacitive retention of approximately $99.5 \%$ after 10,000 cycles. We have also shown its functioning in the form of a symmetric device showing Tassar cocoon, a nitrogen-doped carbon source that can be used to develop different kinds of charge storage devices.

\section{Conclusion}

Comparison of Tassar cocoon with Jute shows how structural differences along with the addition of nitrogen influence the electrical properties of a carbon-based material. This would open a totally new field for business of wild cocoon which otherwise remains confined in the textile industry.

Acknowledgement MD and DP acknowledge the ISRO funding to carry out this research work. This work is part of AD's doctoral thesis.

Open Access This article is distributed under the terms of the Creative Commons Attribution 4.0 International License (http://creativeco mmons.org/licenses/by/4.0/), which permits unrestricted use, distribution, and reproduction in any medium, provided you give appropriate credit to the original author(s) and the source, provide a link to the Creative Commons license, and indicate if changes were made.

\section{References}

1. Frackowiak, E., Béguin, F.: Electrochemical storage of energy in carbon nanotubes and nanostructured carbons. Carbon 40(10), 1775-1787 (2002). https://doi.org/10.1016/S0008-6223(02)00045 $-3$
2. Kötz, R., Carlen, M.: Principles and applications of electrochemical capacitors. Electrochim. Acta 45(15-16), 2483-2498 (2000). https://doi.org/10.1016/S0013-4686(00)00354-6

3. Lin, T., I-Wei, C., Liu, F., Yang, C., Bi, H., Xu, F., Huang, F.: Nitrogen-doped mesoporous carbon of extraordinary capacitance for electrochemical energy storage. Science 350(6267), 15081513 (2015)

4. Pandolfo, A.G., Hollenkamp, A.F.: Carbon properties and their role in supercapacitors. J. Power Sources 157(1), 11-27 (2006). https://doi.org/10.1016/j.jpowsour.2006.02.065

5. Downie, A., Crosky, A., Munroe, P.: In: Lehmann, J., Joseph, S. (eds.) Biochar for Environmental Management: science and technology, Earthscan, VA (2009)

6. Dubey, A., Philip, D., Das, M.: A sustainable, eco-friendly charge storage device from bio-charred jute: An innovative strategy to empower the jute farmers of India. Research into design for communities, volume 2; proceeding of ICORD17. Systems and technologies, vol. 66, pp. 397-407. Springer Nature Publication, Singapore (2016). ISSN 2190-3018; ISBN 978-981-10-3517-3

7. Roy, M.K., Kusurkar, T.S., Maurya, S.K., Meena, S.K., Singh, S.K., Sethy, N., Bhargava, K., Sharma, R.K., Goswami, D., Sarkar, S., Das, M.: Graphene oxide from silk cocoon: a novel magnetic fluorophore for multi-photon imaging. 3 Biotech 4(1), 67-75 (2014). https://doi.org/10.1007/s13205-013-0128-2

8. Saxena, M., Sarkar, S.: Synthesis of carbogenic nanosphere from peanut skin. Diam. Relat. Mater. 24, 11-14 (2012). https://doi. org/10.1016/j.diamond.2012.01.035

9. Sahu, V., Grover, S., Tulachan, B., Sharma, M., Srivastava, G., Roy, M., Saxena, M., Sethy, N., Bhargava, K., Philip, D., Kim, H., Singh, G., Singh, S.K., Das, M., Sharma, R.K.: Heavily nitrogen doped, graphene supercapacitor from silk cocoon. Electrochim. Acta 160, 244-253 (2015). https://doi.org/10.1016/j.elect acta.2015.02.019

10. Saxena, M., Sarkar, S.: Involuntary graphene intake with food and medicine. RSC Adv. 4(57), 30162-30167 (2014). https://doi. org/10.1039/c4ra04022h

11. Sonkar, S.K., Saxena, M., Saha, M., Sarkar, S.: Carbon nanocubes and nanobricks from pyrolysis of rice. J. Nanosci. Nanotechnol. 10(6), 4064-4067 (2010). https://doi.org/10.1166/jnn.2010.2007

12. Arvind, D., Hegde, G.: Activated carbon nanospheres derived from bio-waste materials for supercapacitor applicationsa review. RSC Adv. 5, 88339-88352 (2015). https://doi. org/10.1039/c5ra19392c

13. Biswal, M., Banerjee, A., Deo, M., Ogale, S.C.: From dead leaves to high energy density supercapacitors. Energy Environ. Sci. 6, 1249-1259 (2013). https://doi.org/10.1039/c3ee22325f

14. Chen, J., Liu, Y., Li, W., Xu, L., Yang, H., Li, C.M.: Nitrogenenriched carbon sheets derived from egg white by using expanded perlite template and its high-performance supercapacitors. Nanotechnology 26(34), 345401 (2015). https://doi.org/10.1088/09574484/26/34/345401

15. Ling, Z., Yu, C., Fan, X., Liu, S., Yang, J., Zhang, M., Wang, G., Xiao, N., Qiu, J.: Freeze-drying for sustainable synthesis of nitrogen doped porous carbon cryogel with enhanced supercapacitor and lithium ion storage performance. Nanotechnology 26(37), 374003 (2015). https://doi.org/10.1088/0957-4484/26/37/374003

16. Luo, Q.-P., Huang, L., Gao, X., Cheng, Y., Yao, B., Hu, Z., Wan, J., Xiao, X., Zhou, J.: Activated carbon derived from melaleuca barks for outstanding high-rate supercapacitors. Nanotechnology 26(30), 304004 (2015). https://doi.org/10.1088/09574484/26/30/304004

17. Ma, G., Yang, Q., Sun, K., Peng, H., Ran, F., Zhao, X., Lei, Z.: Nitrogen-doped porous carbon derived from biomass waste for high-performance supercapacitor. Biores. Technol. 197, 137-142 (2015). https://doi.org/10.1016/j.biortech.2015.07.100

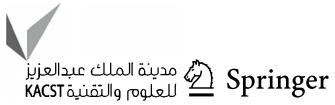


18. Sodtipinta, J., Amornsakchai, T., Pakawatpanurut, P.: Nanoporous carbon derived from agro-waste pineapple leaves for supercapacitor electrode. Adv. Nat. Sci. Nanosci. Nanotechnol. 8, 035017 (2017). https://doi.org/10.1088/2043-6254/aa7233

19. Yun, Y.S., Park, M.H., Hong, S.J., Lee, M.E., Park, Y.W., Jin, H.-J.: Hierarchically porous carbon nanosheets from waste coffee grounds for supercapacitors. ACS Appl. Mater. Interfaces 7(6), 3684-3690 (2015). https://doi.org/10.1021/am5081919

20. Dubey, A., Singh, S.K., Tulachan, B., Roy, M., Srivastava, G., Philip, D., Sarkar, S., Das, M.: Nano iron pyrite $\left(\mathrm{FeS}_{2}\right)$ exhibits bifunctional electrode character. RSC Adv. 6, 16859-16867 (2016). https://doi.org/10.1039/c6ra01973k

21. Ghosh, M., Sonkar, S.K., Saxena, M., Sarkar, S.: Carbon nanoonions for imaging the life cycle of Drosophila melanogaster. Small 7(22), 3170-3177 (2011). https://doi.org/10.1002/ smll.201101158

22. Niu, F., Xu, Y., Liu, M., Sun, J., Guo, P., Liu, J.: Bottom-up electrochemical preparation of solid-state carbon nanodots directly from nitriles/ionic liquids using carbon-free electrodes and the applications in specific ferric ion detection and cell imaging. Nanoscale 8(10), 5470-5477 (2016). https://doi.org/10.1039/ c6nr00023a

23. Dimiev, A.M., Bachilo, S.M., Saito, R., Tour, J.M.: Reversible formation of ammonium persulfate/sulfuric acid graphite intercalation compounds and their peculiar raman spectra. ACS Nano 6(9), 7842-7849 (2012). https://doi.org/10.1021/nn3020147

24. Zhao, W., Tan, H.T., Liu, J., Ferrari, A.C.: Intercalation of fewlayer graphite flakes with $\mathrm{FeCl} 3$ : Raman determination of fermi level, layer by layer decoupling, and stability. J. Am. Chem. Soc. 133(15), 5941-5946 (2011). https://doi.org/10.1021/ja110939a

25. Dimiev, A.M., Tour, J.M.: Mechanism of graphene oxide formation. ACS Nano 8(3), 3060-3068 (2014). https://doi.org/10.1021/ nn500606a

26. Perazzolo, V., Durante, C., Pilot, R., Paduano, A., Zheng, J., Rizzi, G.A., Martucci, A., Granozzi, G., Gennaro, A.: Nitrogen and sulfur doped mesoporous carbon as metal-free electro catalysts for the in situ production of hydrogen peroxide. Carbon 95, 949-963 (2015). https://doi.org/10.1016/j.carbon.2015.09.002

27. Brandiele, R., Picelli, L., Pilot, R., Causin, V., Martucci, A., Rizzi, G.A., Isse, A.A., Durante, C., Gennaro, A.: Nitrogen and sulfur doped mesoporous carbons, prepared from templating silica, as interesting material for supercapacitors. ChemistrySelect 2(24), 7082-7090 (2017). https://doi.org/10.1002/slct.201701404

28. Favaro, M., Perini, L., Agnoli, S., Durante, C., Granozzi, G., Gennaro, A.: Electrochemical behavior of $\mathrm{N}$ and Ar implanted highly oriented pyrolytic graphite substrates and activity toward oxygen reduction reaction. Electrochim. Acta 88, 477-487 (2013). https ://doi.org/10.1016/j.electacta.2012.10.100

29. Bao, L., Zang, J., Li, X.: Flexible $\mathrm{Zn}_{2} \mathrm{SnO}_{4} / \mathrm{MnO}_{2}$ core/shell nanocable-carbon microfiber hybrid composites for high-performance supercapacitor electrodes. Nano Lett. 11(3), 1215-1220 (2011). https://doi.org/10.1021/nl104205s
30. Bao, L., Li, X.: Towards textile energy storage from cotton T-shirts. Adv. Mater. 24(24), 3246-3252 (2012). https://doi. org/10.1002/adma.201200246

31. Gao, Z., Song, N., Li, X.: Microstructural design of hybrid CoO@ $\mathrm{NiO}$ and graphene nano-architectures for flexible high performance supercapacitors. J. Mater. Chem. A 3(28), 14833-14844 (2015). https://doi.org/10.1039/c5ta03057a

32. Gao, Z., Song, N., Zhang, Y., Li, X.: Cotton textile enabled, all-solid-state flexible supercapacitors. RSC Adv. 5(20), 15438 15447 (2015). https://doi.org/10.1039/c5ra00028a

33. Gao, Z., Bumgardner, C., Song, N., Zhang, Y., Li, J., Li, X.: Cotton-textile-enabled flexible self-sustaining power packs via roll-to-roll fabrication. Nat. Commun. 7, 11586 (2016). https:// doi.org/10.1038/ncomms11586

34. Gao, Z., Zhang, Y., Song, N., Li, X.: Towards flexible lithiumsulfur battery from natural cotton textile. Electrochim. Acta 246, 507-516 (2017). https://doi.org/10.1016/j.electacta.2017.06.069

35. Gao, Z., Song, N., Zhang, Y., Li, X.: Cotton-textile-enabled, flexible lithium-ion batteries with enhanced capacity and extended lifespan. Nano Lett. 15(12), 8194-8203 (2015). https://doi. org/10.1021/acs.nanolett.5b03698

36. Gao, Z., Schwab, Y., Zhang, Y., Song, N., Li, X.: Ferromagnetic nanoparticle-assisted polysulfide trapping for enhanced lithiumsulfur batteries. Adv. Funct. Mater. 28, 1800563 (2018). https:// doi.org/10.1002/adfm.201800563

37. Gao, Z., Zhang, Y., Song, N., Li, X.: Biomass-derived renewable carbon materials for electrochemical energy storage. Mater. Res. Lett. 5(2), 69-88 (2016). https://doi.org/10.1080/21663 831.2016.1250834

38. Zhang, Y., Gao, Z., Song, N., Li, X.: High-performance supercapacitors and batteries derived from activated banana-peel with porous structures. Electrochim. Acta 222, 1257-1266 (2016). https://doi.org/10.1016/j.electacta.2016.11.099

39. Zhang, Y., Gao, Z., Li, X.: Capillarity composited recycled paper/ graphene scaffold for lithium-sulfur batteries with enhanced capacity and extended lifespan. Small 13, 1701927 (2017). https ://doi.org/10.1002/smll.201701927

40. Zhang, Y., Heim, F.M., Song, N., Bartlett, J.L., Li, X.: New insights into mossy li induced anode degradation and its formation mechanism in Li-S batteries. ACS Energy Lett. 2(12), 2696-2705 (2017). https://doi.org/10.1021/acsenergylett.7b00886

41. Jangir, H., Pandey, M., Jha, R., et al.: Sequential entrapping of Li and $\mathrm{S}$ in a conductivity cage of $\mathrm{N}$-doped reduced graphene oxide supercapacitor derived from silk cocoon: a hybrid Li-S-silk supercapacitor. Appl. Nanosci. (2018). https://doi.org/10.1007/s1320 4-018-0641-z

Publisher's Note Springer Nature remains neutral with regard to jurisdictional claims in published maps and institutional affiliations. 